Marquette University

e-Publications@Marquette

College of Nursing Faculty Research and

Publications

Nursing, College of

$11-1-2008$

\title{
Reducing Sexual Risk with Practice of Periodic Secondary Abstinence
}

Kristin Haglund

Marquette University, kristin.haglund@marquette.edu

Accepted version. Journal of Obstetric, Gynecologic, \& Neonatal Nursing, Vol. 37, No. 6 (November/ December 2008): 647-656. DOI. (C) 2008 Wiley. Used with permission. 


\section{Reducing Sexual Risk with Practice of Periodic Secondary Abstinence}

Author: Kristin Haglund

\section{Abstract:}

Objective: Test a novel intervention to help sexually experienced girls increase abstinence behaviors and attitudes.

Design: A quasi-experimental repeated measures design using qualitative and quantitative data.

Setting: Two alternative public schools.

Participants: Thirty-three females whose mean age was 16 and who were $79 \%$ African American participated. Most (79\%) had experienced a pregnancy.

Intervention: A 6 session, weekly, interactive intervention was delivered. Data were collected at baseline, last session, and at 5 and 7 month follow-ups.

Main Outcome Measures: Measured outcomes related to abstinence included participants' reasons, behaviors, stages of change, and attitudes.

Results: The most common reason for abstinence was not wanting to have sex. At each postintervention data collection point, most participants (greater than or equal to 74\%) reported that they had purposefully avoided sex. Duration of consecutive days of abstinence increased although only significantly at 5 month follow-up. Abstinence behaviors increased with the largest change from first to last session. Stage of change advanced from preparation to action by 7 month follow-up. Attitudes toward abstinence became more favorable.

Conclusion: Effective sexual risk reduction interventions are critically needed to promote safety. Nurses may assist young women to decrease their sexual risks by teaching them to practice periodic abstinence.

From 2001 to $2005,22,320$ people between the ages of 13 and 24 years were diagnosed with HIV infections in 33 states that conducted confidential, name-based HIV/AIDS surveillance (Durant et al., 2007). These figures do not include residents of 17 states such as California and Illinois and those who have not been tested. An estimated 20,000 new HIV infections occur annually among persons aged 13 to 24 years, but it is assumed that more than $50 \%$ of these infected teens and young adults have not been tested and are unaware of their status (Branson et al., 2006; Rotheram-Borus \& Futterman, 2000; Weinstock, Berman, \& Cates, 2004).

1 Haglund 
Persons of color have been disproportionately affected by HIV/AIDS. From 2001 to 2005, African American teens and adults made up 13\% of the population in the 33 testing states, yet accounted for $51 \%$ of newly diagnosed HIV/AIDS cases (Durant et al., 2007). Between 2000 and 2003, the rate of HIV infection in non-Hispanic Black females was 20 times greater than the rate among non-Hispanic White females and five times the rate among Hispanic females (Durant et al.). Most (76\%) persons infected with HIV are men. However, in one study of disadvantaged youth, young women aged 16 to 21 years had a $50 \%$ higher prevalence rate of HIV than young men of the same ages (Valleroy, MacKellar, Karon, Janssen, \& Hayman, 1998). For adolescent and adult women, the predominant mode of transmission is heterosexual contact. Adolescent females are at increased risk for HIV infection due to unsafe sexual practices, immature vaginal epithelium, and sexual involvement with adult men.

There is an urgent need for interventions to assist young women who are sexually active to decrease their risks. Abstinence, condom use, and decreasing the number of sexual partners are methods to reduce risks for contracting HIV (Singh, Darroch, \& Bankole, 2003). In the United States, most interventions that include abstinence are focused on encouraging youths to delay sexual initiation. The majority of these interventions have not been successful in assisting sexually experienced youths to return to abstinence, to achieve long-term reductions in frequency of sexual activity, or decrease number of partners (Aten, Siegel, Enaharo \& Auinger, 2002; Jemmott \& Jemmott, 2000; Kirby, Korpi, Adivi, \& Weissman, 1997; Kirby, Laris, \& Rolleri, 2007). Recently, a review of 83 experimental or quasi-experimental studies of curriculum-and group-based sex or HIV education programs for youths aged 9 to 24 years old was published. Approximately $90 \%$ of the included studies encouraged abstinence and included content on condoms or other contraceptives for youths who chose to be sexually active. Of the remaining $10 \%, 7 \%$ were abstinence-only projects and $3 \%$ were focused on condoms only.

Two outcomes pertinent to sexually experienced youths included reduction in frequency of intercourse and reduction in number of partners measured in 31 and 34 of the included studies, respectively. A significant reduction in frequency of intercourse was reported in only $29 \%$ of the 31 studies that measured frequency of intercourse. Reduction in number of partners was reported in only $35 \%$ of the 34 studies that measured number of sexual partners. In the remaining studies, $65 \%$ to $71 \%$, lack of significant change in these abstinence outcomes was reported which may be attributed to a variety of reasons. The review authors identified that approximately $50 \%$ of the included studies lacked sufficient power to detect meaningful program effects on behavior (Kirby et al. 2007). Another problem may be that abstinence education is

2 Haglund 
generally delivered to large groups in school settings. Some youths may be committed to engaging in sexual activity and others have negative attitudes about abstinence which may decrease their acceptance of the interventions (Haglund, 2006; Ott, Pfeijer, \& Fortenberry, 2006). Finally, lack of change in behaviors underscores the need for new approaches to assist youths who have already experienced intercourse to choose and to practice abstinence.

This pilot study was an attempt to test a new way to teach abstinence. Periodic abstinence was promoted as a strategy to lower sexual risk by decreasing genital contact and number of partners. In this study, periodic meant that one was abstinent for a length of time that was preceded, and would be followed by, periods of sexual activity. Periodic abstinence was presented as another option to decrease sexual risks. Participants were encouraged to add abstinence to their existing practices of condom and contraception use; however, didactic content on the use of condoms and contraceptives was not included in this program. This novel intervention was tested with sexually experienced adolescent females of whom most $(79 \%)$ had been, or were currently, pregnant. The research questions were whether after receiving instruction on specific strategies, do sexually experienced adolescent girls (a) increase abstinence behaviors and (b) exhibit more favorable attitudes about abstinence?

\section{Theoretical Framework}

The conceptual framework was the five-stage transtheoretical model of change (DiClemente et al., 1991; Hulton, 2001; Norcross \& Prochaska, 2002). In the first stage, precontemplation, persons are either unaware of, or underestimate, a problem behavior and have no serious intention to change. In contemplation, the second stage, individuals become aware of a problem and begin to think about changing their behavior. The third stage is preparation when an individual has an intention to change within the next month or may have engaged in some action toward change but not achieved the final goal. Individuals in the fourth, or action stage, have committed to change and have successfully changed their behavior for a period of 1 day to 6 months. The fifth and final stage, maintenance, is when a person has achieved behavior change and has sustained that change for more than 6 months.

\section{The Intervention}

The author was the principal investigator (PI) who worked with a team of graduate pediatric nursing students to create a data-based curriculum called "Helping Youths to Choose and Maintain Sexual Abstinence." This intervention was designed as a booster to the

3 Haglund 
comprehensive sexuality education that the students had already received. Topics included defining sex and abstinence, strategies for choosing and maintaining abstinence, and suggestions for parents to help youths be abstinent. The curriculum consisted of power point slides, hand-outs, and activities. There were six interactive sessions and each included discussion questions, case studies, and exercises. Participants learned how to choose and practice abstinence periodically when the time was right for them. A neutral tone was achieved by avoiding describing abstinence as the most moral or the most effective choice for adolescents.

It is recommended that one match the process of change to the clients' stage of change (Norcross \& Prochaska, 2002). In this study, participants progressed as a group through the same series of processes of change, regardless of individual stages of change. However, the curriculum was matched to a hypothetical participant beginning in the precontemplation stage and moving through to the action stage by the end of the sessions.

Defining sex and abstinence included activities such as consciousness raising and selfreevaluation, which tend to be most effective to assist people to move from precontemplation to contemplation and then to preparation (Norcross \& Prochaska, 2002). A series of slides and discussion led up to definitions of sex and abstinence. To prevent infections and pregnancy, sex was defined as oral-, anal-, object-, or genital-genital contact with a partner of the same or opposite gender. Sexual abstinence was defined as a lifestyle choice in which one committed to the purposeful avoidance all genital contact for a period of time identified by an individual according to personally determined needs. One may choose abstinence at any time, even after having had sex.

In choosing strategies, participants were led through a discussion of the benefits, or pros, of practicing abstinence. The pros and cons of changing a behavior are important in the transtheoretical model. In most cases, people must decide that the pros outweigh the cons before they take action to modify their behavior (Prochaska et al., 1994). After talking about why someone might choose abstinence, strategies for making this choice were presented in a fourstep process. The steps were to (a) assess one's sexual risks, (b) examine one's safer sex practices, (c) determine if abstinence was desired, and (d) set a goal. Participants identified periods of time when abstinence might be the best choice, such as the postpartum period before contraception was started, when their partner was out of town or, when they were not in a stable relationship. Long-term or vague time frames for duration of abstinence were not promoted. Long-term goals, such as until marriage, may not be desirable to young women and 4 Haglund 
vague goals, such as "until I'm ready" or "until I'm grown up," are difficult to evaluate and meet. Participants were encouraged to set realistic, short-term goals for periods of time that met their needs, whether that was 1 day, 1 week, or 6 months. Once met, they were advised to revaluate their commitment, and if desired, set new, personal abstinence goals.

Behavioral processes were emphasized in strategies for maintaining abstinence, which is appropriate for persons in the action stage (Prochaska \& DiClemente, 1983). Maintenance strategies included how to manage challenges such as romantic partner pressure, peer pressure, media influences, and the impacts of drugs and alcohol. Practical behavioral strategies were identified to handle risk situations and to avoid sex. Finally, the parenting topic was tailored to the participants, most of whom were mothers of young children. Strategies were discussed to prepare these mothers to talk to their children about sex and abstinence.

Alterations in the participants' reasons for abstinence, behaviors, and stages of change, were measured. Hypotheses were formulated regarding levels of abstinence behaviors and reasons for abstinence at each stage of change including (a) participants in the precontemplation and contemplation stages will indicate few reasons and behaviors, (b) those in the preparation stage will have small increases in reasons and behaviors, (c) in the action stage participants will report substantial increases in both measures, and (d) in the maintenance stage prior levels will persist with little further increase in reasons or behaviors.

\section{Method}

\section{Design}

A quasi-experimental repeated measures design using qualitative and quantitative data was used. Human subjects approval was obtained from appropriate boards.

\section{Project Team}

The PI was an experienced advanced practice nurse with expertise in caring for African American youths and families and a specialty in adolescent health care. A community health educator ( $\mathrm{CHE}$ ) experienced in sexuality education assisted the PI with presentation of the sessions and with quantitative data collection. The PI and CHE were White. A female, undergraduate, African American research assistant conducted most of the interviews.

\section{Participants}

The intervention occurred in two alternative schools that enrolled middle and high school students. Students were economically disadvantaged and many had a history of poor school achievement. The convenience sample included 33 young women. Their mean age was 16 with

5 Haglund 
a range of 12 to 19 years. Three (10\%) were in 8th grade, $10(30 \%)$ in 9thgrade,6 (18\%) in 10 th grade, $9(27 \%)$ in 11th grade, and 5 (15\%) in 12th grade. Most were African American (70\%), $15 \%$ reported multiple ethnicities, $6 \%$ were Hispanic, $6 \%$ White, and $3 \%$ Native American. All participants had had sexual intercourse in the past and 26 (79\%) were mothers. Most (82\%) had completed comprehensive sexuality education.

\section{Procedure}

The entire series of the intervention was delivered by the PI and CHE in six, 50 minute sessions over consecutive weeks to groups that ranged from 6 to 13 participants. Participants' responses during discussions were recorded on newsprint and maintained as data. The intervention was delivered to four different groups between March 2006 and January 2007.

A letter was sent home to inform parents that the study was going on in the school and that their child may be invited to participate. The administrators of the schools selected the classes in which the intervention was delivered. All of the students enrolled in the classes were eligible to participate. Students who did not provide their assent and/or parental consent attended the classes but did not participate in data collection. Before the first session, the team visited the classes for introductions. Participant assent was obtained for those less than 18 and consent for those over 18. Parental consents were distributed to those under 18. Parental consents were returned the following week at the first session and baseline surveys were completed. Items were read aloud at the baseline data collection. Participants completed the Reasons for Abstinence Scale, Abstinence Behavior Scale, and Stages of Change Scale at the first and last sessions, and at 5 and 7 months after the first session (see Table 1 for information regarding data collection points). The $\mathrm{PI}$ was present at subsequent collection times to assist with completion of forms as needed. Participants received a $\$ 10$ Wal-Mart gift card after completing data collection at each of the four times and after their interview.

Audiotaped interviews were conducted to obtain qualitative data regarding changes in attitudes toward abstinence and the participants' evaluation of the project. Individual interviews were conducted sometime after the final session in a private room within the school during or after a class period. Each interview lasted15 to30 minutes.

\section{Measures/Instruments}

A confidential identification number was used on the surveys and interview tape. Four instruments were used. The Participant Demographics form was used to collect age, grade,

\section{Haglund}


ethnicity, and sexual history. The Reasons for Abstinence Scale, The Sexual Abstinence Behavior Scale, and The Adolescent Stages of Change Scale for Sexual Abstinence were repeated measures and are described below. See Table 1 for scores.

The Reasons for Abstinence Scale was adapted for this study and used to measure participants' reasons for saying no to having sex (Blinn-Pike, 1999). The original scale included 17 items derived from the literature on adolescent sexual activity. The instrument was used in a study of early adolescents who had never had intercourse. Theta was .84. This scale was adapted for this study to make the questions appropriate for respondents who had already experienced intercourse. The question stem was changed from "I have never had sex" to "I have said no to sex." The revised scale included 20 dichotomous items, 10 items from the original scale and 10 new items (see Table 2). Item revision was based on the PIs' clinical judgment. A nurse practitioner colleague with expertise in primary health care for adolescents reviewed the original and revised scales, which provided face validity. Cronbach's $\alpha$, for the revised scale was .68. a increased to .7 when one item "I was waiting until I am older" was deleted. This item was deleted from analyses. Each yes response on the Reasons for Abstinence Scale was scored as "1." The total score corresponded to the summed number of reasons participants had said no to sex with a possible range of 0 to 19.

The Abstinence Behavior Scale was used as it was originally written to measure changes in abstinence behaviors. It was validated in a study of 113 African American, male and female, 7th grade students (Norris, Clark, \& Magnus, 2003). Reliability assessed with Cronbach's a was .73. Support for construct validity was identified. Four items measured how often in the past 3 months participants told themselves they were making the right decision by waiting to have sex, said no to sex, told a partner they wanted to wait, and avoided pressure to have sex by going out with a group. A 5-point response scale ranging from never to more than once a week was used. The range for the total score was 0 to 16 with never scored as 0 and more than once a week as 4 . Higher scores indicated more abstinence behaviors. In this study, Cronbach's a was .64. An unforeseen issue was identified by a participant who reported that in the last 3 months she had never said no to sex or told a partner that she wanted to wait because she had no partner. She was not having sex, yet she answered the items in the same way as a participant who had said yes to sex each time would have. Her answers resulted in a lower mean score indicating less abstinence behaviors even though she was abstinent. It was unknown how many participants were affected similarly.

The Stages of Change Scale was slightly adapted from the original and was used to

\section{Haglund}


measure the participants' baseline stage of change and movement across the stages of change over time (Hulton, 2001). The original included two subscales, four items for participants who were virgins and five for nonvirgins. Each item was a one-sentence descriptor of behavior and/or intention and corresponded to a stage of change. Content validity index of the original was .82. The present study utilized only the subscale for nonvirgins. Two items were slightly changed to more accurately correspond to the stages of change (DiClemente et al., 1991). Participants in this study were asked to select the one statement that matched how they felt about abstinence on that day. Stage of change was determined by the item selected. Precontemplators reported that they had no desire to stop having sex and had no need to learn abstinence skills. Contemplators reported that they had no immediate need for learning abstinence skills but may want to do so in the next 6 months. Participants in the third stage, preparation, reported that they were learning abstinence skills and planned to use them in the next month. Individuals in the action stage reported that they had a need to learn abstinence skills, had in fact learned some and had practiced them for the last 6 months. Finally, participants in maintenance reported that they had learned abstinence skills and had practiced them for the past 6 months or longer.

\section{Data Analysis}

SPSS 14.0 was used to analyze quantitative data. Descriptive statistics were used to analyze demographic and baseline data. Repeated measures analysis of variance (ANOVA) was used to evaluate alterations in stages of change with $p=.05$. Paired samples $t$ tests were done to determine changes in reasons for abstinence, consecutive days of abstinence, and abstinence behaviors. Number of days abstinent was calculated from baseline to the last session, baseline to 5 month, and baseline to 7 month follow-up. Thus days from baseline to 5 month follow-up overlapped with the days from baseline to last session and ANOVA could not be used with this data. Multiple $t$ tests were used to analyze the reasons for abstinence and the behavior scale changes to preserve sample size. Bonferroni's correction was applied for the multiple $t$ tests and the level of significance was adjusted to $p=.02$.

Seventeen of the 33 participants were interviewed. The remainder declined or were absent when interviews were conducted. Thematic analysis was used to analyze interview data. Transcripts were entered into QSR NVivo 2.0. Initial codes were perceived challenges to abstinence, attitude toward abstinence, and session evaluation. As analysis proceeded, the initial codes were revised to reflect emerging themes. Eventually two major themes were

8 Haglund 
identified. They are described in the Changes in Attitudes section.

\section{Results}

\section{Reasons for Abstinence}

Across data collection points, the top three reasons for abstaining were not wanting to have sex, to avoid AIDS, and to avoid STIs (see Table 2).For each participant, a total number of reasons was calculated at each data collection point (see Table 1). At baseline the mean number of reasons was 8.7. The mean number of reasons increased at the last session and stayed high at the 5-and 7 month follow-ups although these changes were not significant.

\section{Changes in Behaviors}

Following the intervention, participants reported increased abstinence behaviors. At each data collection point, most (74\%-84\%) reported that they had purposefully avoided sex. Participants also reported increased duration of abstinence. A variable was created from the reported last time of sex that represented consecutive days of abstinence. Some participants indicated a date; others stated the number of days, weeks, or months since their last experience. When a range was indicated, such as 2 to 3 weeks, the more proximal period of time was used for this variable. Duration was analyzed as days thus 1 week was equivalent to 7 days and 1 month to 4 weeks or 28 days. Data from one participant were deleted due to inconsistency between reported time of last sex across collection forms. Days of consecutive abstinence increased at each data collection point with a significant increase at the 5 month follow-up. From baseline to last session participants were abstinent a mean of $23(S D=11)$ consecutive days compared with $18(S D=14)$ days for the same time period from before baseline to baseline, $t(28)=-1.9, p=.06$. At the 5 month follow-up, participants had practiced consecutive abstinence for a mean of $91(S D=55)$ days from baseline compared with $64(S D=$ 64) days for the same time period from before baseline to baseline with an effect size of .91, $t(28)=-2.4, p=.02$. Participants were abstinent for a mean of $98(S D=84)$ days from baseline to the 7 month follow-up compared with $77(S D=82)$ days for the same time period from before baseline to baseline $t(21)=-1.2, p=.2$.

Scores of the four items in the Abstinence Behavior Scale were summed. The total score increased significantly at each time of data collection indicating more frequent abstinence behaviors. The largest increase was from baseline to last session with respective mean scores of $6.4(S D=4.2)$ and $8.6(S D=4.5)$ and an effect size of $.44, t(32)=-2.5, p=.02$. Compared with baseline, increases in abstinence behaviors

9 Haglund 
remained significantly high at the 5 month follow-up $(M=9, S D=4.7), t(29)=-2.4$,

$p=.02$ and $d=-.44$. Scores remained high, although not significantly, at the 7 month follow-up $(M=8.8, S D=4.7), t(24)=-2.2, p=.03$. Scores of the individual Abstinence Behavior Scale items increased over time although not significantly.

Stage of change advanced at each time of data collection moving from a mean of preparation at baseline to the action stage at the 7 month follow-up, effect size $\left(\eta^{2}\right)$ of .33, $F(3$, $20)=3.3, p=.04$. At baseline, $39 \%$ were in the action or maintenance stages. This percentage increased to $55 \%$ at last session, $71 \%$ at 5 month follow-up, and $68 \%$ at 7 month follow-up. The action and maintenance stages were defined as having learned abstinence skills and practiced them in the past 6 months or longer. Thus advancing stages of change also represented increased behaviors. Behaviors and reasons were hypothesized to fluctuate with stage of change. The levels increased generally, although not exactly, as hypothesized (see Figure 1).

\section{Changes in Attitudes}

Analysis of interview data revealed two primary themes. Participants described changes in their attitudes about abstinence and their evaluations of the curriculum.

Theme 1: Abstinence is a good choice but often difficult to maintain.

Interviewed participants were unanimously positive about abstinence. Five said that before the program, they thought that abstinence was "lame," "stupid," and "just negative how they tell people don't have sex." These young women as well as the other interviewees reported that after the program they viewed abstinence as a positive choice. One 18 year old said,

Being abstinent is a good thing and it's not what some other people think like "oh if you're not doing it you're weak, you're not grown, you're young and you're a baby" but you're really not. Being abstinent is a way to protect yourself from the dangers that are out there from people who are not abstinent and who are having multiple sex partners.

Generally, the girls viewed being abstinent as a way to respect and value oneself, to prevent repeat pregnancies, and avoid diseases.

Participants talked about their internal questioning regarding their choice to be abstinent. They felt that being abstinent was a choice that could only be made by the individual; a person could not be forced to be abstinent or really even told to be abstinent. As a 17 year old said,

I thought it was interesting. It let the girls know about abstinence, let them learn more about it and let them think about if they should do it or not .... They gave 10 Haglund 
us good points about abstinence and it let me think about if I should do it or not.

All respondents said that they planned to practice periodic abstinence now or in the future.

While participants reported that abstinence was a positive choice, they also acknowledged that it was difficult to practice. They felt it took "will power" to say no and resist pressure to have sex. Nine told stories about times when they had intended to be abstinent but ended up having intercourse anyway. All of the stories involved pressure from their male partners. Reflecting on the stories they told, they were all able to identify things they had learned in class that might have helped them to stay abstinent in those situations. A 15 year old said, "I know that the next time if he tries it again (pressuring her into sex), I wouldn't do it because it was a big mistake. That's why I have a daughter now and I know to say no now so he can't trick me this time. I wouldn't care if he would get mad."

Theme 2: The class was more than what I expected.

All of the interviewed participants reported a positive evaluation of the program. Eight participants reported that they had not learned about abstinence before and knew little about it beyond "don't do it, its bad for you." Others reported that they had learned about abstinence but felt that this program was more detailed and in depth than previous education. In this program, they felt that they had learned benefits of abstinence and how they could practice it if they chose to do so. As one 16 year old said,

Everybody tries to teach us this, but they don't really get to the details. They just say the basics, "wear protection, don't fall into the wrong crowd and do it because everybody else does that around you." This program teaches you a little bit more detail about what can happen and some consequences to these actions. They tell you how it can affect your goal and just because you've done it before it doesn't mean you have to do it again.

One aspect of the program that seemed to be especially valued was the discussion. Participants liked discussing the scenarios, listening to their classmates' experiences and opinions, and sharing their own opinions. As one 18 year old said, "I liked it because I got to participate and I got to get in and share things that I felt and my ideas. And other teens got to hear what each other thought." Suggestions to improve the program included having more sessions that lasted longer and occurred more than once per week. "It's hard not being sexually active so if we had more encouragement and had more support, we would succeed at it," said a 11 Haglund 
15 year old. Small groups were suggested so that everyone would have a chance to speak and be heard. Finally, while it was not a purpose of the program to increase knowledge about STIs and HIV, the participants noted that their knowledge was increased and that this was a major benefit of the program. They recommended that this content be expanded and continue to be included in future renditions of the program.

\section{Discussion}

Few interventions have resulted in large increases in return to prolonged abstinence after initiation of sexual activity (DiCenso, Guyatt, \& Grith, 2002; Jemmott, Jemmott, \& Fong, 1998). In a meta-analysis of $44 \mathrm{HIV}$ risk reduction intervention studies, the frequency of sexual intercourse was significantly decreased, albeit very modestly, with a mean effect size of .05 (95\% Cl, 0.02-0.09) and odds ratio 1.10 (95\% Cl, 1.04-1.17) (Johnson, Carey, Marsh, Levin, \& Scott-Sheldon, 2003). In a second meta-analysis of 19 intervention studies, abstinence behaviors were increased slightly with a mean effect size of .08 and a range from -.05 to .40 (Jemmott \& Jemmott, 2000).

This was a study of a new approach to abstinence education. The curriculum was developed to change negative perceptions and to help participants view abstinence as a reasonable and positive way to decrease sexual risks. This study resulted in significantly increased consecutive days of abstinence and abstinence behaviors with a mean effect size of .53 and a range from .33 to .91 . Attitudes also became more favorable. Participants concluded that abstinence was an effective way to prevent pregnancy and to manage their sexual risks.

In many programs, abstinence is presented as an either/or option (Kirby et al., 2007). That is, one may choose abstinence or choose to have sex and use condoms and contraceptives. In this project, participants were encouraged to combine abstinence, condoms, and contraceptives to maximally decrease their sexual risks. Participants were taught to incorporate abstinence into their lives in practical and workable ways. This project also differed in that participants were encouraged to set short-term, periodic goals for duration of abstinence. This was in contrast to projects that encourage abstinence until marriage. In this study, shortterm goals were encouraged as they provided the opportunity for more immediate success which may have led to increased confidence and inspired further commitment to abstinence. In addition, shorter periods of time were viewed as more realistic for adolescents who tend to think and live "in the moment."

Utilizing a theory-based intervention has been identified as a best practice (Kirby, 2001).

\section{Haglund}


The curriculum in this study corresponded to the stages of change with the initial material targeted toward those in the earlier, contemplative stages and subsequent materials toward action in later stages. This approach worked well for these sexually experienced young women. Rather than dictating a definition of abstinence and mandating practice, the initial materials allowed the participants to conclude for themselves what behaviors abstinence included and that practicing it was possible and beneficial. This facilitated their acceptance and adoption of the later behavioral strategies.

\section{Nursing Implications}

Nurses seeking to help young women who have already experienced intercourse practice abstinence may benefit from these lessons learned. Some young women, as in this study initially, have negative perceptions of abstinence. Others believe that abstinence is synonymous with virginity and therefore it is something that they can no longer achieve. Thus, it is important to assess how a client feels about abstinence before suggesting that they try it. A forthright conversation may help them to view abstinence more favorably, which could facilitate acceptance of the information.

When suggesting abstinence, nurses may frame it as one of three options for reducing sexual risk. This normalizes abstinence and removes some of the emotional and moralistic connotations of this word. A neutral conversation may encourage a teen to speak more honestly about her feelings. Convey that to avoid pregnancy and STIs, practicing abstinence entails avoidance of all genital contact with a male or female partner. Brainstorm alternate ways to share affection. Help the young woman to identify times in her life when abstinence would work and provide practical suggestions for behavior changes as well as strategies for managing risk situations. Engage in frequent conversations about sex and abstinence to increase knowledge and encourage conscious avoidance of sexual risks. Participants in this study and others valued speaking openly with knowledgeable adults about sexuality issues (Haglund, 2006).

\section{Limitations and Future Research}

This pilot study was limited by its small size, short-term follow-up and quasi-experimental design. The low alpha on the Abstinence Behavior Scale increased the risk of accepting a false null hypothesis or a type II error. Still, the positive results support further testing of this intervention. A randomized controlled trial is being planned.

\section{Haglund}




\section{References}

Aten, M. J., Siegel, D. M., Enaharo, M., \& Auinger, P. (2002). Keeping middle school students abstinent: Outcomes of a primary prevention intervention. Journal of Adolescent Health, 31(1), 70-78.

Blinn-Pike, L. (1999). Why abstinent adolescent report they have not had sex: Understanding sexually resilient youth. Family Relations, 48, 295-301.

Branson, B., Handsfield, H., Lampe, M., Janssen, R., Taylor, A., Lyss, S., et al. (2006). Revised recommendations for HIV testing of adults, adolescents and pregnant women in healthcare settings. Morbidity and Mortality Weekly Report, 55(RR141), 1-17.

DiCenso, A., Guyatt, G., \& Griffith, W. (2002).Interventions to reduce unintended pregnancies among adolescents: Systematic review of randomized controlled trials. British Medical Journal, 324, 1426-1430.

DiClemente, C., Prochaska, J., Fairhurst, S., Velicer, W., Velasquez, M., \& Rossi, J. (1991). The process of smoking cessation: An analysis of precontemplation, contemplation, and preparation stages of change. Journal of Consulting and Clinical Psychology, 59, 295304.

Durant, T., McDavid, K., Hu, X., Sullivan, P., Janssen, R.,\&Fenton, K.(2007). Update to racial/ethnic disparities in diagnoses of HIV/AIDS-33 states, 2001-2005. Morbidity and Mortality Weekly Report, 56, 189-193.

Haglund, K. (2006). Recommendations for sexuality education for early adolescents. Journal of Obstetric, Gynecologic \& Neonatal Nursing, 35, 369-375.

Hulton, L. (2001).The application of the transtheoretical model of change to adolescent sexual decision-making. Issues in Comprehensive Pediatric Nursing, 24, 95-115.

Jemmott, J., \& Jemmott, L. (2000). HIV risk reduction behavioral interventions with heterosexual adolescents. AIDS, 14(Suppl. 2), S40-S52.

Jemmott, J., Jemmott, L., \& Fong, G. (1998). Abstinence and safer sex HIV risk reduction interventions for African American adolescents. Journal of the American Medical Association, 279, 1529-1536.

Johnson, B., Carey, M., Marsh, K., Levin, K., \& Scott-Sheldon, L. (2003). Interventions to reduce sexual risk for the human immunodeficiency virus in adolescents, 1985-2000. Archives of Pediatric and Adolescent Medicine, 157, 381-388.

Kirby, D. (2001). Emerging answers: Research findings on programs to reduce teen pregnancy (summary). American Journal of Health Education, 32, 348-355.

14 Haglund 
Kirby, D., Laris, B., \& Rolleri, I. (2007). Sex and HIV education programs: Their impact on sexual behaviors of young people throughout the world. Journal of Adolescent Health, 40, 206217.

Norcross, J., \& Prochaska, J. (2002). Using the stages of change. Harvard Mental Health Letter, 18, 5-7.

Norris, A., Clark, L., \& Magnus, S. (2003). Sexual abstinence and the sexual abstinence behavior scale. Journal of Pediatric Health Care, 17, 140-144.

Ott, M., Pfeiffier, E., \& Fortenberry, J. (2006). Perceptions of sexual abstinence among high-risk early and middle adolescents. Journal of Adolescent Health, 39, 192-198.

Prochaska, J., \& DiClemente, C. (1983). Stages and processes of self-change of smoking: Toward an integrative model of change. Journal of Consulting and Clinical Psychology, 5, 390-395.

Prochaska, J., Velicer, W., Rossi, J., Goldstein, M., Marcus, B., Rakowski, W., et al. (1994).Stages of change and decisional balancefor12 problem behaviors. Health Psychology, 13, 39-46.

Rotheram-Borus, M., \& Futterman, D. (2000). Promoting early detection of human immunodeficiency virus infection among adolescents. Archives of Pediatric and Adolescent Medicine, 154, 435-439.

Singh, S., Darroch, J., \& Bankole, A. (2003). A, B, C, in Uganda: The roles of abstinence, monogamy and condom use in HIV decline. Occasional Report, 9. Retrieved November 2, 2007, from http://www. agi-usa.org

Valleroy, L., MacKellar, D., Karon, J., Janssen, R., \& Hayman, C. (1998). HIV infection in disadvantaged out-of-school youth: Prevalence for U.S. Job Corps entrants, 1990 through 1996. Journal of Acquired Immune Deficiency Syndromes and Human Retrovirology, 19, 67-73.

Weinstock, H., Berman, S., \& Cates, W. (2004). Sexually transmitted diseases among American youth: Incidence and prevalence estimates, 2000. Perspectives on Sexual and Reproductive Health, 36, 6-10.

\section{Notes:}

Kristin Haglund, PhD, RN, APRN, BC is an assistant professor, Marquette University, College of Nursing, Milwaukee, WI.

\section{Appendix}

15 Haglund 
Table 1

Data Collection Points and Instrument Scores

\begin{tabular}{|l|c|c|c|c|}
\hline \multicolumn{1}{|c|}{$\begin{array}{c}\text { Data Collection } \\
\text { Points }\end{array}$} & $\begin{array}{c}\text { First Session } \\
(N=33)\end{array}$ & $\begin{array}{c}\text { Last Session } \\
(N=33)\end{array}$ & $\begin{array}{c}5 \text { month Follow-up } \\
(N=31)\end{array}$ & $\begin{array}{c}7 \text { month Follow-up } \\
(\mathrm{N}=25)\end{array}$ \\
\hline $\begin{array}{l}\text { Mean months from } \\
\text { baseline }\end{array}$ & - & $1 \pm 0.3^{\mathrm{b}}$ & $5 \pm 0.6$ & $7 \pm 0.8$ \\
\hline $\begin{array}{l}\text { Mean months from } \\
\text { last session }\end{array}$ & - & - & $4 \pm 0.6$ & $6 \pm .07$ \\
\hline $\begin{array}{l}\text { Instrument scores } \\
\text { (Range) }\end{array}$ & $M(S D)$ & $M(S D)$ & $M(S D)$ & $M(S D)$ \\
\hline $\begin{array}{l}\text { Reasons for } \\
\text { Abstinence (0-19) }\end{array}$ & $8.7(3.7)$ & $10.1(3.4)$ & $10.5(4.5)$ & $10.0(4.0)$ \\
\hline $\begin{array}{l}\text { Abstinence Behavior } \\
\text { Scale }(0-16)\end{array}$ & $6.4(4.2)$ & $8.6(4.5)$ & $9.0(4.7)$ & $8.8(4.7)$ \\
\hline $\begin{array}{l}\text { Told self waiting was } \\
\text { right (0-4) }\end{array}$ & $2.2(1.4)$ & $2.5(1.4)$ & $2.6(1.3)$ & $2.6(1.3)$ \\
\hline Said no to sex (0-4) & $2.3(1.2)$ & $2.5(1.4)$ & $2.6(1.3)$ & $2.7(1.3)$ \\
\hline $\begin{array}{l}\text { Asked a partner to } \\
\text { wait (0-4) }\end{array}$ & $1.9(1.4)$ & $1.9(1.6)$ & $2.1(1.5)$ & $2.0(1.5)$ \\
\hline $\begin{array}{l}\text { Out in a group to } \\
\text { avoid pressure (0-4) }\end{array}$ & $1.4(1.7)$ & $1.8(1.8)$ & $1.7(1.6)$ & $1.5(1.8)$ \\
\hline $\begin{array}{l}\text { Stages of change (1- } \\
5)\end{array}$ & $3.3(1.2)$ & $3.5(.08)$ & $3.7(1.3)$ & $3.9(1.0)$ \\
\hline
\end{tabular}

Note.

Interview occurred after the last session $(N=17)$.

${ }^{b}$ Sessions were generally 6 consecutive weeks, except for accommodations for school schedules.

'Total score.

16 Haglund 
Table 2

Reasons for Abstinence

\begin{tabular}{|c|c|c|c|c|}
\hline \multirow{2}{*}{\begin{tabular}{|l|} 
Question Stem \\
\end{tabular}} & \multicolumn{4}{|c|}{$N(\%)$ Responding Yes } \\
\hline & $\begin{array}{l}\text { First Session } \\
\quad(N=33)\end{array}$ & $\begin{array}{l}\text { Last Session } \\
\quad(N=33)\end{array}$ & \begin{tabular}{|c}
5 month Follow-Up \\
$(N=31)$
\end{tabular} & $\begin{array}{c}7 \text { moth Follow-UP } \\
(N=25)\end{array}$ \\
\hline \multicolumn{5}{|c|}{ "I said no to sex because..." } \\
\hline $\begin{array}{l}\text { I did not want to have } \\
\text { sex }\end{array}$ & $28(85)$ & $29(88)$ & $29(94)$ & $21(84)$ \\
\hline $\begin{array}{l}\text { I did not want to get } \\
\text { AIDS }\end{array}$ & $23(70)$ & $28(85)$ & $22(71)$ & $19(76)$ \\
\hline $\begin{array}{l}\text { I did not want to get a } \\
\text { disease }\end{array}$ & $22(67)$ & $27(82)$ & $22(73)$ & $20(80)$ \\
\hline I was on my period & $22(67)$ & $24(73)$ & $20(65)$ & $15(60)$ \\
\hline $\begin{array}{l}\text { I was waiting for the } \\
\text { right person }\end{array}$ & $22(67)$ & $20(61)$ & $21(68)$ & $16(64)$ \\
\hline $\begin{array}{l}\text { We did not have a } \\
\text { condom }\end{array}$ & $16(49)$ & $20(61)$ & $17(55)$ & $14(56)$ \\
\hline $\begin{array}{l}\text { I did not want to get } \\
\text { preanant aqain }\end{array}$ & $16(49)$ & $22(67)$ & $22(71)$ & $20(80)$ \\
\hline $\begin{array}{l}\text { To focus on my school } \\
\text { work }\end{array}$ & $15(46)$ & $21(64)$ & $20(65)$ & $18(72)$ \\
\hline $\begin{array}{l}\text { I broke up with my } \\
\text { partner }\end{array}$ & $14(42)$ & $14(42)$ & $13(42)$ & $12(48)$ \\
\hline $\begin{array}{l}\text { I did not want to upset } \\
\text { my parents }\end{array}$ & $13(39)$ & $13(39)$ & $12(39)$ & $8(32)$ \\
\hline $\begin{array}{l}\text { My partner refused a } \\
\text { condom }\end{array}$ & $13(39)$ & $18(56)$ & $13(42)$ & $9(36)$ \\
\hline $\begin{array}{l}\text { My partner was out of } \\
\text { town or in jail }\end{array}$ & $12(36)$ & $15(46)$ & $15(48)$ & $12(48)$ \\
\hline $\begin{array}{l}\text { I was not on birth } \\
\text { control }\end{array}$ & $12(36)$ & $15(46)$ & $12(39)$ & $14(56)$ \\
\hline $\begin{array}{l}\text { I was too busy taking } \\
\text { care of my child }\end{array}$ & 11 (33) & $13(39)$ & $23(74)^{\star *, a, b}$ & $16(64)$ \\
\hline I was pregnant & $10(30)$ & $13(39)$ & $10(32)$ & $5(20)$ \\
\hline I just had a baby & $9(27)$ & $14(42)$ & $16(52)^{\star, a}$ & $10(40)$ \\
\hline $\begin{array}{l}\text { I am waiting until } \\
\text { married }\end{array}$ & $6(18)$ & $8(24)$ & $10(32)$ & $5(20)$ \\
\hline $\begin{array}{l}\text { My friends think I } \\
\text { shouldn't have sex }\end{array}$ & $5(15)$ & $5(15)$ & $4(13)$ & $3(12)$ \\
\hline $\begin{array}{l}\text { My religion says its } \\
\text { wrong to have sex } \\
\text { before marriage }\end{array}$ & $4(12)$ & $4(12)$ & $6(19)$ & $5(20)$ \\
\hline
\end{tabular}

Note

${ }^{\mathrm{a}}$ Significant change from baseline.

${ }^{\mathrm{b}}$ Significant change from Time 2.

${ }^{*} p \leq .02$.

** $p \leq .01$.

17 Haglund 
Figure 1

Reasons for abstinence, behaviors and stages of change over time.

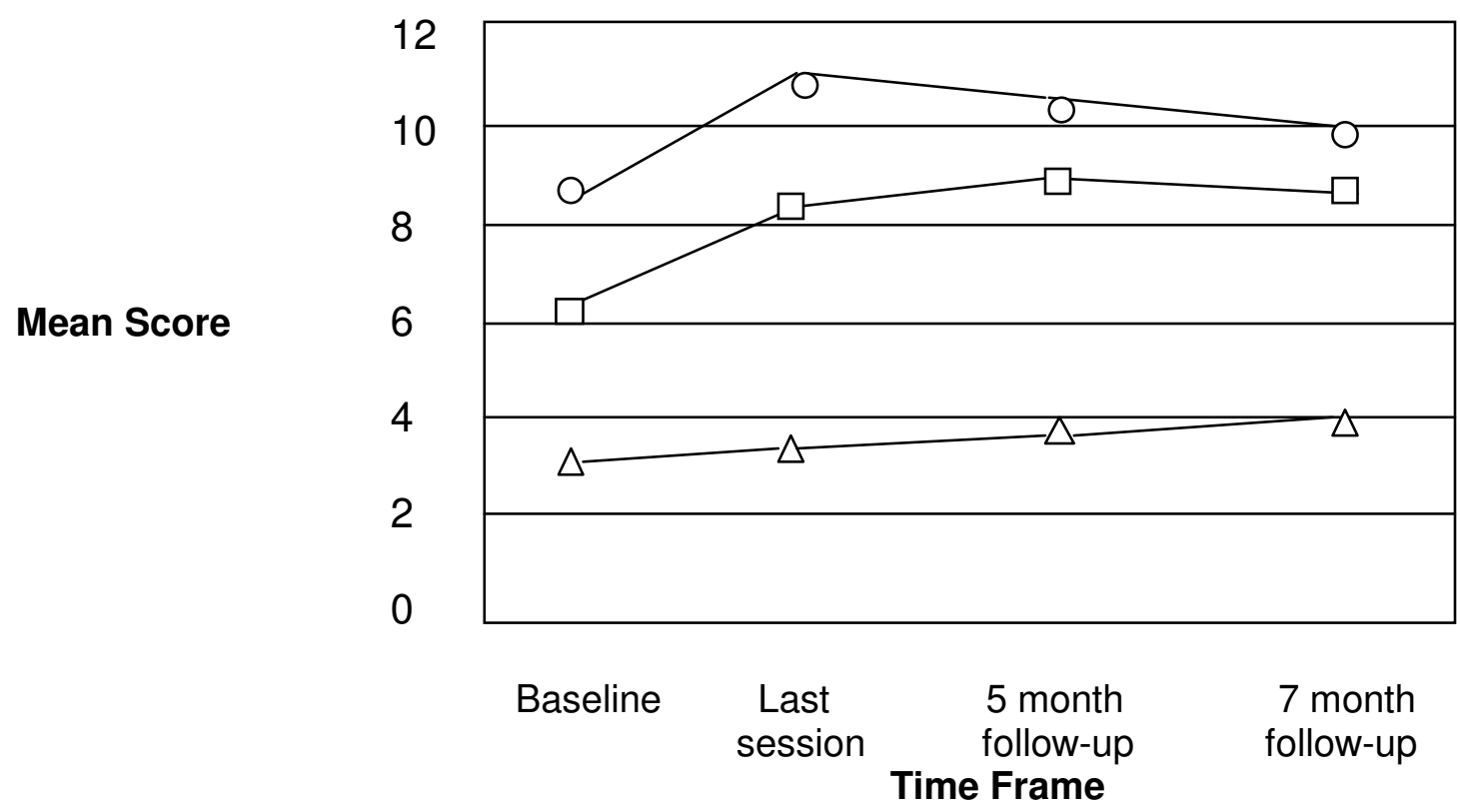

Reasons $\bigcirc$

Behaviors $\square$

Stages of Change $\triangle$

18 Haglund 